\section{La resistencia:}

\section{"decisiones de SER}

para educar" *

\author{
A resistência: "decisões do SER \\ para educar"
}

\section{The resistance: "BE decisions to educate"}

\section{Resumen}

En la investigación "Sentidos entre-tejidos: una aproximación a la subjetividad política en maestrosy maestras", se encontró que la resistencia, uno de los rasgos de la subjetividad política, se configura biográficamente mediante experiencias de subjetivación constantes vividas en el escenario de lo público, en el marco de la pluralidad, y a partir de referentes éticos, morales y políticos que le permiten al sujeto asumir una actitud de transformación de sí mismo y del mundo. En los procesos de subjetivación, la conciencia de sí y del mundo posibilita comprender la propia historia, reconocer mecanismos de dominación de los que se ha sido objeto y redireccionar las relaciones que se establecen en la intersubjetividad como un estilo de existencia.

\section{Palabras clave}

Resistencia, subjetivación, subjetividad política.

\section{Resumo}

Na pesquisa "Sentidos Entre-Tecidos: Uma abordagem para a subjetividade política em professores e professoras" descobriu-se que a resistência, uma das características da subjetividade política, configura-se biograficamente através de experiências de subjetivação constantes vividas no cenário do público, no âmbito da pluralidade, e a partir de padrões da ética, da moral e da política que lhe permitem ao sujeito assumir uma atitude de transformação de si mesmo e do mundo. Nos processos de subjetivação, a consciência de si mesmo e do mundo possibilitam ao sujeito compreender a própria história, reconhecer os mecanismos de dominação dos quais tem sido objeto, e redirecionar as relações estabelecidas na intersubjetividade, como um estilo de existência.

\section{Palavras chave}

resistência, subjetivação, subjetividade politica. ación "Sentidos entretejidos: una aproximación a la subjetividad política en maestros y maestras", que se realizó para optar al título de magister en Educación y Desarrollo Humano del CINDE en convenio Universidad de Manizales.

** Magister en Educación y Desarrollo Humano, CINDE-Universidad de Manizales. Docente universitaria, Facultad de Educación del Tecnológico de Antioquia, y docente de educación media; Medellín, Colombia. Correo electrónico lausanfre@hotmail.com.

\section{Abstract}

In the researching "Senses between-tissue: An approach to political subjectivity in teachers", it was found that the resistance, a feature of political subjectivity is biographically configured through experiences lived in constant subjection stage of the public, in the context of plurality, and from ethical, moral and political references that allow the subject to take an attitude of self-transformation and the world. In the processes of subjectivity, consciousness of self and the world allows you to understand the story itself, recognize the mechanisms of domination that has been, and redirect the relations established in intersubjectivity, as a way of existence.

\section{Key words}

resistance, subjectivity, political subjectivity.
Fecha de recepción: 28 de febrero de 2014 Fecha de aprobación: 31 de mayo de 2014 
En una sociedad desfigurada por la explotación, la opresión, el peligro crónico de guerra y de destrucción ambiental, la única educación que se merece tal nombre, es aquella que forma gente capaz de tomar parte de su propia liberación.

\section{H. Giroux}

$\mathrm{N}$ os encontramos ante un presente injusto e incierto de un mundo donde día a día se diseñan estrategias para romper los lazos entre individuos, para provocar la indiferencia y promover que unos caigamos sobre otros en una lucha por la supervivencia que hace prevalecer al homo laborans, y que lleva a la desaparición del mundo común. En nombre de la razón hemos alcanzado la sinrazón de poner a los seres humanos en la condición de medios para alcanzar los fines más altos que plantea la sociedad de consumo, y mediante la razón hemos llegado a la enajenación de la realidad.

Como seres humanos objetivados, replicamos una y otra vez formas relacionales, prácticas y discursos que nos convierten en sujetos pasivos, sin voluntad, sin capacidad de juicio y concentrados en sí mismos.

No obstante, no nos embarga la desesperanza pues aún tenemos un recurso, rescatar al sujeto, recuperar su humanidad, liberar su subjetividad constreñida, y favorecer actos libertarios y transformadores que devuelvan la dignidad de la vida y la de cada ser. He aquí uno de los grandes retos de la escuela de hoy, he aquí tal vez la principal tarea que tenemos maestros y maestras, la de aportar a la configuración de subjetividades activas, reflexivas, resistentes y transformadoras de esta realidad. Además, la esperanza vuelve a nosotros cuando podemos dar cuenta de docentes cuyas acciones políticas en el aula van en esta dirección, al ser sujetos resistentes a la reificación del mundo, sujetos que aportan a la construcción de mundos soñados haciendo de sus aulas de clase esferas públicas donde se teje la política, se experimenta la pluralidad y se arma el mundo común.

Este artículo se deriva de la investigación "Sentidos entre-tejidos: una aproximación a la subjetividad política de maestros y maestras" (2013), ejercicio fenomenológico-hermenéutico en el que, mediante la técnica de relatos autobiográficos, construidos a través de entrevistas conversacionales, se buscó acceder a los sentidos y significados que los y las participantes asignan a los acontecimientos que en su vida les han llevado a configurar una subjetividad política y que despliegan en su ejercicio de maestros/as.

En esta investigación, la subjetividad política como categoría central es una construcción en la que aportan diferentes autores, de manera especial Alvarado,
Ospina, Botero y Muñoz (2008), quienes establecen diferencias puntuales entre una subjetividad política y una subjetividad subalterna, precisando esta última como pasiva, conformista, acrítica y propia del mundo de lo privado - en términos arendtianos- de un sujeto que no se asume como agente del mundo que habita, que solo se ve a sí mismo, y que por lo tanto es estática. En contraposición, la subjetividad política implica una disposición distinta frente a sí mismo y frente al mundo; se define como una subjetividad activa, reflexiva, crítica, resistente, de esperanza y, de manera especial, en relación con otros y otras; en términos de los autores, propia de un sujeto real.

Dentro de los hallazgos de la investigación cabe resaltar dos aspectos centrales, el primero, que la subjetividad política de los maestros y maestras participantes se configura a partir de cuatro rasgos que son: la pluralidad, la resistencia, la conciencia histórica y la alteridad; el segundo, que en cada uno de ellos y ellas, a partir de sus experiencias biográficas, uno de los rasgos se instala como central nucleando y potenciando los demás rasgos.

Este artículo se centra en la resistencia como rasgo central de una de las maestras participantes y pretende desarrollar la siguiente tesis: La resistencia se configura biográficamente con la mediación de una experiencia de subjetivación constante, a partir de referentes morales, éticos y políticos, que ponen al sujeto en un lugar de transformación de sí y del mundo. Para su efecto, en el primer apartado se tratará de evidenciar la manera en que la resistencia configurada como eje central en la subjetividad política potencia los demás rasgos de su subjetividad, a la vez que se caracteriza este rasgo retomando la voz de los y las participantes de la investigación; en el segundo, se abordará cómo una actitud de resistencia permea las prácticas de aula.

\section{La resistencia como eje que articula los demás rasgos de la subjetividad política}

Como ya se dijo, uno de los hallazgos fundamentales de la investigación es que la subjetividad política de los maestros y las maestras participantes se configura biográficamente a partir de cuatro rasgos: la pluralidad, la conciencia histórica, la resistencia y la alteridad, y en cada uno de ellos y ellas un rasgo se vuelve central nucleando y potenciando los demás, por eso hablar de uno de los rasgos implica mostrar sus entrecruzamientos con los otros. En Juana, una de las participantes, la resistencia emerge como rasgo central y a través de procesos de subjetivación se convierte en una actitud propia de su personalidad. 
El concepto de resistencia es retomado a partir de Foucault (citado por Cubides, 2006), quien la define como un conjunto de luchas transversales que afirman el derecho a ser diferentes, que atacan lo que rompe los lazos del individuo con los otros y lo que constriñe la subjetividad. Es la respuesta de un sujeto que al instalarse políticamente en el mundo confronta las lógicas y formas de dominación y control; es la existencia de posibilidades contrarias a la normalización, a los procesos de subjetivación institucionalizados y al gobierno de la individualización. La resistencia tiene por objeto la imposición de cierto tipo de identidad y la sumisión de la subjetividad.

La resistencia se estructura a partir de las reflexiones del sujeto sobre las propias vivencias, convirtiéndolas en experiencias que sustentan sus decisiones y orientaciones en el mundo. Es una reacción contundente, desde el sentir, ante cosas que no están bien en el mundo, que exigen desacomodarse y, con una actitud crítica y coherente, ocupar un lugar de desacuerdo activo, superando la sumisión y la pasividad. No aflora a partir de divagaciones teóricas y construcciones conceptuales, aunque se alimenta de ellas, sino de apropiaciones que pasan por la piel a través de los sentidos, de lo que se ha experimentado en la propia biografía y en la de otros con quienes se comparte la existencia, por eso puede afirmarse que quien resiste es un sujeto cuerpo a quien le duele el mundo:

\footnotetext{
Simplemente me han tocado cosas de la vida que a uno lo ubican y que le dicen, bueno usted va a tomar posición o no va a tomar posición, y yo siempre he tratado de hacerlo actuando en coherencia con lo que pienso [...] Yo siento que logro darme cuenta de cuán inconsciente era, termino dándome cuenta que esos discursos en los que yo incluso llego a formar a otros, eran discursos que iban en contra de todas las cosas que yo era y que yo podía ser... entonces ya me pongo a pensar mucho que no es justo y que es muy duro que ese tipo de cosas pasen, pues que uno esté adoctrinado y que esté adoctrinando a otros sin darse cuenta en qué, y que uno al menos debería tener la opción de poder decir, eh, hay otras cosas para elegir... yo aprendí que desde el discurso se pueden hacer resistencias, desde la investigación se pueden hacer resistencias mucho más interesantes y de hacer devoluciones sociales de lo que uno ha recibido (Profesora Juana, entrevista con la autora, 2013)
}

El sujeto resistente confronta aquello que le ha sido presentado de manera objetivada en su mundo de base, y en los submundos o realidades parciales interiorizadas posteriormente; lee el mundo con una lógica crítica para no dejarse encasillar y realiza múltiples interpretaciones de lo que acontece, haciendo del pensamiento un requisito para la acción y desarrollando la capacidad de juicio político, como se evidencia a continuación:

Yo en el colegio empecé a ver todo eso, que hablaban de democracia y nunca teníamos la palabra, que hablaban de respetar al otro y una cantidad de atropellos que uno dice, no, pues mientras que en mi casa todo lo contrario a eso... allí había una relación más equilibrada con nosotros, como iguales como persona (Profesora Juana, entrevista con la autora, 2013)

Como afirman Berger y Luckman (2001), en la realidad de la vida cotidiana, en la intersubjetividad, el sujeto internaliza el mundo como una realidad social significativa; en ella, las estructuras, las lógicas y los referentes dados como el mundo se convierten en los parámetros con los que cada ser se moverá en el mismo; sin embargo, es posible acceder a otras significaciones y a la construcción de nuevos universos simbólicos en tanto el sujeto encuentre suficiente credibilidad y coherencia como para ubicarse en un lugar de resistencia con lo que ha sido previamente objetivado, para establecer juicios morales frente a las realidades vividas.

Esos criterios de decisión, desde los cuales el sujeto resistente se desacomoda y se dispone a la acción, son alimentados y forman un tejido de trama densa con una conciencia histórica que le permite acceder a comprensiones y explicaciones lógicas de las estructuras de la realidad, para entender por qué las cosas son o funcionan de cierta manera; se conoce el mundo para cambiarlo, y se toma conciencia de las lógicas propias de la cultura para enfrentarlas y transformarlas. La conciencia histórica posibilita desarrollar una capacidad de juicio, que en términos de Arendt (1997) implica pensar desde el punto de vista del otro y asumir la pluralidad que somos; como espectadores de un mundo común, juzgar es pensar con mentalidad extensa, poniéndonos en el lugar del otro, pero pensar por sí mismos; por eso el juzgar solo es posible en un espacio potencialmente público, desde el cual disponerse con actitud firme ante lo que debe ser el mundo,

Lo que me ha hecho de verdad tomar una postura, es haber aprendido el método materialista dialéctico, eso es lo que me ha permitido mirar la realidad desde otra óptica, buscar no quedarme en las apariencias sino tratar de buscar las causas; esa manera de ver la vida hace que uno aprenda a tomar postura desde la relación con mi compañero, con mi hija, la relación con el trabajo, la relación con el sindicato, todo ha hecho que tenga esta posición [...] haberme 
tocado la operación Orión con los muchachos, ver matar los niños, ver que los vistieron de camuflados, que aparecieron de falsos positivos, toda esa guerra con los bombardeos en los helicópteros todo ese asunto, pues uno no puede quedarse sin posición... Cogían a todos los muchachos y los amarraban así en la subida en postes, todo el día los muchachos al sol y al agua, entonces son cosas que lo hacen a uno tomar posición. Entonces ahí me parece que acaba de reafirmarse todo esto... luego en la divisa pos-operación Orión, igual, pues las condiciones no cambiaron, que les hubieran dado empleo, vivienda, no, pues la guerra siguió. La guerra siguió soterra$\mathrm{da}$, las condiciones de las familias igual (Profesora Juana, entrevista con la autora, 2013)

Gracias a la conciencia histórica se revela un mundo social e históricamente construido, un mundo resultado de acciones humanas en el transcurrir del tiempo, develando así el sentido de la dialéctica de la realidad y la posibilidad de ser transformada mediante su agenciamiento. Desde la resistencia y accediendo a la conciencia histórica el sujeto se reconoce contextuado e histórico, sale de su propio yo, pone la mirada en los otros del mundo al reconocer discursos, poderes, y acciones naturalizadas que afectan a muchos y no solo a sí mismo; formula preguntas que antes no tenía, se hace consciente de cosas de su propia existencia, de exclusiones y dominaciones compartidas y, en este caso específico, del papel que juega el maestro en la sociedad, disponiéndose a no descuidar su ejercicio ni abandonar la pregunta por quién es. Así, la conciencia histórica y la resistencia se anudan en una sola madeja que desacomoda al sujeto y le pone en un lugar de acción; las comprensiones del mundo aportan elementos para saberse situado y responsabilizarse con el devenir, son una fuerza de resistencia y una herramienta para la construcción del sujeto agente.

La conciencia histórica teje un puente entre pasado y futuro, como plantea Gadamer (1993), convirtiéndola en el fundamento para la construcción del mundo propio y social; comprender y explicar las realidades del mundo permite además hacer visibles a muchos otros que (también) padecen dolores e injusticias, pues al develarse la verdad se develan esos "otros" con quienes se habita el mundo. La explicación-comprensión del mundo des-automatiza al sujeto, lo saca de la lógica instrumental en la que lo inserta el sistema y por esta vía se humaniza, se sensibiliza frente a los demás, se devela el rostro del mundo que deviene en resistencia. Mediante las narraciones del mundo no solo se saben y repiten las historias, sino que ante todo se desarrolla esa capacidad de juicio necesaria para actuar en él, para desacomodarse y generar un compromiso político frente a lo que acontece.

Con Ricoeur hay que decir (2005) que la interpretación del mundo es un proceso de pensamiento que va de la explicación a la comprensión; en su búsqueda el sujeto se desplaza en un ritmo incesante entre el campo de las significaciones del texto del mundo, de los signos de la humanidad y el sentido o proposición de mundo que se ofrece, llegando finalmente al sí propio, al cuestionamiento del sentido de la vida y a la pregunta por la dirección que debe tomar, y que en últimas le permite comprenderse mejor.

Descongelar el mundo por la vía de la conciencia histórica e identificar opciones de transformación a través de la acción resistente alimenta un sentimiento de esperanza hacia otros mundos posibles, mundos más justos, más solidarios y respetuosos, más humanos, donde se dignifique la existencia, donde se supere el sentido instrumental en el que se ha puesto a cada ser y donde la vida en colectivo cobre sentido e importancia. Como afirma una de las maestras participantes, desde el lugar de la resistencia "solo el desencanto y la inconformidad puede salvarnos", solo así podremos construir nuevos caminos, formas alternativas a las actuales, como politizar el mundo, la escuela, la familia, y reconstruirlas bajos nuevas lógicas.

Pero las reflexiones que permiten descongelar el mundo y develarlo compartido no son el resultado de monólogos en solipsismo sino de construcciones en colectivo, en escenarios de socialización donde por la vía de la palabra y en comunidad académica se aborda la realidad. En ese estar con otros, vivido en el marco familiar y de los amigos o en escenarios de acción colectiva en los que se fortalece la acción conjunta, se alcanza un reconocimiento como sujeto público, como un alguien que puede poner en juego su palabra y su acción, y con ello recoger elementos para pensarse a sí mismo y al mundo, para hacerse cargo de su voluntad y emprender acciones para la transformación:

[...] fue con ellos, mis hermanos y mi compañero, y el asunto en la universidad, pero desde la universidad no, por eso es que decimos que uno va a la universidad pero no solo a clase, o sea lo que se mueve en la universidad es el cine, el teatro, la cafetería, las personas tan diversas que uno se encuentra... el aprendizaje fue más en los grupos de estudio, en participar en las asambleas, en escuchar que se podían hacer asambleas, que el estudiante tiene palabra, ahí yo me entendí como un sujeto, que ya era una profesional pero no para resolver mi problema individual solamente, eso no quiere decir que no estuviera preocupada por mi problema individual, 
pero que ese no era lo más importante; sino que era necesario pensarse y transformarlo (entrevista con la autora, 2013).

La resistencia además de requerir de la pluralidad y de la esfera pública a manera de escenario para su configuración, potencia la emergencia de las mismas como condiciones de aparición con otros/as, como requisitos para garantizar una realidad del mundo desde la que es posible crear otras realidades. La creación de la esfera pública es necesaria como escenario en el que pueden unirse las fuerzas de muchos/ as dejando de lado, como afirma Arendt (2005), los intereses privados para tener en cuenta el punto de vista de los demás, para compartir interpretaciones $\mathrm{y}$ con ello permitir que se devele cada quien en un espacio común. A partir del rasgo de la resistencia el sujeto político busca revelar su iniciativa de crear algo nuevo para el mundo, lo cual solo puede darse mediante la acción y el discurso en la esfera de los asuntos humanos, en el entre-nos, y en condiciones de pluralidad.

En dicho espacio común se afianza el sujeto político con la posibilidad de la palabra y de la acción, y a través de estas se logran comprensiones de la realidad que por sí mismo el sujeto no alcanza pues carece de la perspectiva plural que ofrecen los demás, ya que solo conversando en colectivo se hace visible el mundo, como lo explica Arendt (1997):

Lo decisivo de la libertad de hablar, de hablar los unos con los otros, no es de ninguna manera que cada cual pudiera decir lo que quiera, o que cada hombre tenga el derecho inherente a expresarse tal como sea. Aquí de lo que se trata más bien es de darse cuenta de que nadie comprende adecuadamente por sí mismo y sin sus iguales lo que es objetivo en su plena realidad porque se le muestra y manifiesta siempre en una perspectiva que se ajusta a su posición en el mundo y le es inherente. Sólo puede ver y experimentar el mundo tal como éste es "realmente" al entenderlo como algo que es común a muchos, que yace entre ellos, que los separa y los une, que se muestra distinto a cada uno de ellos y que, por este motivo, únicamente es comprensible en la medida en que muchos, hablando entre sí sobre él, intercambian sus perspectivas. (p. 79)

En cuanto la resistencia es una reivindicación de la acción, es una exigencia de la esfera pública, único lugar donde se hace efectiva la libertad como posibilidad del sujeto para ser y hacer, y consecuentemente es un rescate de la pluralidad. Como afirman García, Restrepo y Urrego (2013) la acción está concebida como acto de creación, como fuerza e impulso, como novedad que requiere de un espacio de reconocimiento para poder emerger y que solo puede darse en el entre-nos; en este sentido, la resistencia propende por la pluralidad, condición humana en la que cada uno hace su aparición en el mundo de lo púbico mediante acción y discurso y lleva a cabo su segundo nacimiento, que es requisito para la acción porque sin mundo común no hay política. Al propender por el rescate de la dignidad y de las posibilidades propias y de los "otros", la resistencia rescata la pluralidad y la experiencia política.

Las experiencias de aparición como sujeto público, en el marco de la pluralidad, donde cada uno/a pueda ser reconocido y validado ante los demás mediante el derecho a la palabra y la acción, hacen posible la comprensión de un mundo compartido en el que se visibiliza la existencia de otros/as como otro legítimo, principal distinción para un sujeto político, apropiándose de principios fundamentales para la vida en el entre-nos como el reconocimiento, la solidaridad y la libertad, las cuales no ordenan un mundo para sí mismos sino un mundo compartido.

Tales experiencias en la esfera pública permiten la construcción de horizontes de sentido desde los cuales el sujeto habla y actúa conforme a lógicas de un nuevo orden y, en consecuencia, aporta a la construcción de espacios donde la pluralidad sea una realidad, que resiste para enfrentar la carencia de estos principios y escenarios.

De acuerdo con lo anterior, es posible afirmar que en la base del sujeto político que resiste en un mundo normalizado y homogenizado, que toma decisiones para asumir formas de existencia más conscientes y humanizadas, se halla un sujeto moral en quien la construcción del sentido del bien y de lo justo toca con lo humano. Esta posición que deriva en acción aflora a partir de las distinciones morales realizadas desde unos marcos referenciales que sirven de orientación en el espacio moral, que son el trasfondo de sus juicios, intuiciones y valoraciones acerca de lo que se establece como bueno y valioso, y que aportan los significados del mundo (Taylor, 1996). Los marcos referenciales le permiten al sujeto pensarse en una relación consigo mismo y con otros y otras porque son tejidos en la intersubjetividad, en el mundo del entre-nos, en el que se definen y redefinen las orientaciones de la vida moral a medida que devenimos como sujetos:

En la experiencia formativa en el semillero de investigación empezamos a ver diferentes discursos, y entonces son preguntas más amplias que yo antes de eso ni siquiera había podido entender, preguntas más por lo social que solo por lo personal... ya no era solamente yo, con lo que yo quería ser, sino que 
ya soy yo reivindicándome como sujeto político con derechos, y luego sabiendo que además de eso tengo obligaciones políticas y sociales, o sea ya era como otra dimensión [...] quienes me criaron no fueron tan cultos, pero sí sabían del respeto, sí sabían que el otro estaba ahí (entrevista con la autora, 2013).

En la configuración de la subjetividad política y del rasgo de la resistencia, las distinciones entre lo correcto y lo incorrecto y entre el bien y el mal, juegan un papel fundamental para definir lo que es importante o banal, lo que tiene sentido en la existencia o no, y con ello determinar qué lugar ocupar en el mundo; estas distinciones son la base para discernir en la cotidianidad una orientación hacia un sentido del bien general. Tanto los criterios y orientaciones de la vida moral como la manera en que se construyen son una base importante para desplegar una actitud de resistencia, pues cuando los significados del bien y de la justicia son construcciones colectivas en condiciones de reconocimiento mutuo, el sentido de la moral vincula con el otro y le asigna un lugar en la propia existencia; por eso en el espacio del mundo común, que une y separa al mismo tiempo a individuos singulares, en el marco de la pluralidad, es donde se gestan los principios morales y la acción política del sujeto resistente.

Puede afirmarse que la experiencia de la pluralidad es fundamental para la construcción de una idea del bien colectivo, para la configuración de subjetividades resistentes a la deshumanización, porque la construcción de sentidos y significados morales en común generan una ampliación del círculo ético al hacerle visible al sujeto un mundo que es compartido, en el que cada vez hay un mayor número de personas cuyas vidas importan, no por su cercanía, sino por su humanidad. De acuerdo con Alvarado (2012), la ampliación del círculo ético es la capacidad de reconocerse plural en lo común, es cuando la propia identidad obliga a una vida en común, al entre-nos, configurando un sujeto político.

Leer y vivir el mundo en perspectiva plural permite reconocer y contrastar diferentes formas de ser, de vivir y de pensar y elegir entre ellas desplegando una capacidad de autodeterminación para decidir cómo actuar. Los escenarios de socialización en condiciones de pluralidad posibilitan hacerse públicos/ as mediante la acción y el discurso, ser visibilizados/ as, vivir en medio de palabras y de la persuasión y ser reconocidos/as como sujetos con posibilidades de decisión; en diálogo con Arendt (2005), permiten hacer el segundo nacimiento, en el mundo de lo público. Por eso, retomando a esta autora, es necesario decir que la pluralidad es condición de toda vida política y, en consecuencia, de la configuración de una subjetividad política resistente, en cuanto concierne al estar con otros/as en condiciones de iguales y distintos al mismo tiempo, es requisito para la vida en común.

Gracias a las experiencias en espacios constituidos como esferas públicas, el sujeto político comprende que provocar las transformaciones no es un asunto de idealizaciones sino de acciones que se gestan y concretan en escenarios colectivos, por la vía del discurso y de la palabra, por la vía de la deliberación, y de allí se derivan formas de resistencia contra las relaciones de poder, que validan a unos y niegan a otros, y contra los discursos adoctrinadores.

Tal actitud de resistencia en contra de las dominaciones, las injusticias y la individualización, le ha permitido a esta maestra desplegar también el rasgo de la alteridad, entendida como acogida y hospitalidad de los otros y las otras por fuera de cualquier contrato previo, asumiéndolos como un compromiso ineludible; esto significa tejer lazos que unen existencialmente con esos otros, ocuparse de ellos y darles un lugar; como dice Restrepo:

En la experiencia de alteridad el otro es reconocido como alguien, no como algo, con quien se quiere establecer una relación de acogida, reconocimiento, responsabilidad, que me permite descubrirme en mi propia singularidad y diferencia, pero además valorar las alternativas y los universos de sentidos que el otro me expresa. (2013, p. 5)

Esta disposición a hacerse responsable de otros y otras obedece, como ya se dijo, a una ampliación del círculo ético y al reconocimiento de la condición de humanidad de los demás, reconociéndose el sujeto en un mundo compartido, del cual también es responsable: "[...] ahí tocaba que la clase era simplemente una excusa para acercarse al muchacho y ver cómo le ayudaba a sobrevivir en esa situación tan horrible" (entrevista con la autora, 2013).

Como puede evidenciarse, los rasgos de la subjetividad política se tejen a lo largo de la biografía de Juana en una trama densa desde la resistencia, que los enlaza y reorienta en permanente fluir; así, resistencia, conciencia histórica, pluralidad y alteridad, son diferentes hilos de un mismo tejido que configuran un sujeto político, un sujeto de acción.

En consecuencia, las luchas de un sujeto resistente son un rechazo a las formas de poder que determinan quién es uno. De acuerdo con esto, la resistencia como rasgo de la subjetividad política está en relación directa con procesos de subjetivación, es decir, con la autoconfiguración de la subjetividad a partir de decisiones y orientaciones propias, pues lo que se 
pone en juego al resistir es el "cómo orientar la acción en situaciones concretas que se presentan"(Gadamer, 1993) reflexiones que, como afirma este autor, remiten al sujeto a la clarificación de la propia conciencia y le permiten ubicarse en un lugar de acción frente a sus propias experiencias, frente a sí mismo y a los otros/as, hacerse cargo de su voluntad y dirigir la propia vida:

[...] entonces eso me hizo tomar también una determinación en mi vida: yo quiero ser así, yo no quiero seguir diciendo una cosa y haciendo otra como yo lo veía por ejemplo en el colegio, o como yo lo veía en otros espacios. [...] si queremos una revolución del imperio tiene que empezar por cada sujeto (entrevista con la autora, 2013).

Estos procesos de subjetivación, siguiendo a Foucault (citado por Cubides, 2006), son acciones que el sujeto ejerce sobre sí mismo y por las cuales se hace cargo de sí, se modifica y se transfigura; son prácticas meditadas y voluntarias mediante las cuales procura transformarse para resistir a la individualización y a la dominación. Tales procesos tienen implicaciones éticas en cuanto hay una reorientación consciente y voluntaria del propio estilo de existencia y de la forma de vida que se quiere asumir, además de implicaciones políticas, ya que el sujeto revisa y reorienta las formas relacionales de sí mismo con los otros. Así, la subjetivación deriva en un sujeto que se autoconstituye a partir de decisiones existenciales derivadas del entre-nos, en un sujeto crítico de sus propias acciones, en un sujeto no enajenado sino subjetivado.

En un ejercicio de reflexividad, en un ir y venir entre la conciencia de sí y la conciencia del mundo, el sujeto que tiene actitud de resistencia decide cómo quiere ser y qué quiere hacer, llevando a cabo procesos de subjetivación haciéndose subversivo de su propia historia e implicándose en la transformación de formas sociales y políticas deseables.

\section{La resistencia, rasgo que transfigura al ser y su rol}

La tarea de quien enseña a vivir y a convivir es, justamente, la de responder éticamente a la existencia del otro.

\section{SKLIAR}

Desde un lugar de resistencia mediado por experiencias de pluralidad, el maestro se enfrenta a las prácticas y a los discursos que al interior de la escuela invisibilizan, coartan y niegan a los sujetos, así como al sentido instrumental y mecanicista de la educación; en contravía transfigura su rol haciendo del aula una esfera pública, un espacio para la pluralidad, de posibilidad para la palabra y la acción, por las cuales cada sujeto se convierte en una promesa para el mundo al instalar algo nuevo en el mismo. Convierte el aula en escenarios de socialización donde cada uno pueda verdaderamente ser un quien ante los demás, un interlocutor válido, validado en su diferencia y de esta manera aporta a la configuración de sujetos activos, capaces de pensar de manera reflexiva y crítica.

Así, Juana resiste por una educación humanizada y humanizadora, por darle un carácter político a la práctica docente, fomentando otro tipo de relaciones con los y las estudiantes, y reconociendo en cada uno de ellos su capacidad de palabra y de acción como vía para llevar a cabo lo infinitamente improbable; aportando por el despliegue de múltiples subjetividades, por la configuración de subjetividades políticas:

[...] que los muchachos no están sentados en fila, sino que yo ubico las sillas todos los días en círculo; ¿por qué? porque no nos vamos a dar la espalda, nos vamos a mirar, todos vamos a ver qué es lo que pasa, el aprendizaje es un asunto colectivo, aquí no hay nadie más teso que otro, sino que simplemente ha tenido más acercamiento con lo que se está trabajando, y simplemente así vamos a ver cómo se hace (entrevista con la autora, 2013).

En este sentido, humanizar la escuela como expresión de resistencia es garantizar la política allí, es decir, la existencia del mundo común que une y separa al mismo tiempo a todos y todas; porque política en términos arendtianos (1997) significa libertad para hablar y actuar, posibilidad de ser y aparecer ante otros, y de esa manera poder tejer vínculos entre diversos en medio de relaciones de reconocimiento. Y la pluralidad, condición básica para la acción y el discurso en perspectiva arendtiana, es una vía para resistir y enfrentar las formas homogenizantes e individualizantes que buscan ser instaladas por la sociedad acabando con el homo políticus aristotélico que humaniza, en cuanto desde la acción cada sujeto puede agenciar el mundo común y emprender algo nuevo en el mismo, y desde el discurso es posible expresar quiénes somos, develando así la distinción que nos caracteriza. Además, y como afirma Arendt (1997), a través de la palabra y la acción se logran comprensiones de la realidad que por sí mismo el sujeto no alcanza pues carece de la perspectiva plural que ofrecen los demás; solo conversando en colectivo se hace visible el mundo.

La resistencia es la vía para que un maestro como sujeto político se oponga a la reproducción de discursos que homogenizan, y a estructuras que no permiten la participación en la construcción 
del mundo común. Desde el lugar de la resistencia, maestras y maestros tienen elementos para liberar antes que constreñir subjetividades, para favorecer la emergencia de subjetividades plurales, reflexivas y conscientes que permitan a cada sujeto tomar distancia con la historia personal y colectiva que le enmarca, y para disponerse a la creación de otras nuevas y de mundos mejores.

Por eso, en la configuración de subjetividades resistentes, se hace fundamental contar con experiencias de pluralidad en las que se devele la existencia de otros/as en la esfera pública y donde haya espacio para la acción y el discurso como requisitos fundamentales para la vida en común, permitiendo que se evidencie la condición de distintos e iguales al mismo tiempo para enfrentar la homogenización y el individualismo, y en las que se instale en el sujeto una pregunta por el otro/a, que emerge a partir de una idea de bien que lo configuran como un sujeto moral.

La escuela tiene la tarea de comprometerse con la formación de niños, niñas y jóvenes sujetos de acción, sujetos críticos que se conviertan en una promesa para el mundo porque pueden añadir algo nuevo al mismo, alimentando así la esperanza de la transformación. Pero esto requiere de maestros/as como sujetos políticos que resisten a discursos y prácticas que constriñen la subjetividad, ciudadanos de la escuela, potenciadores de ciudadanías y constructores de mundos posibles, a quienes les quepan muchas significaciones del mundo y no solo las propias, maestros capaces de subjetivarse y reconfigurar también su rol.

Afirmar que a la escuela no le corresponde asumir una postura política como la resistencia es afirmar que no le corresponde preocuparse por los asuntos del mundo y aportar en su transformación. Es urgente que maestros y maestras en sus aulas emprendan acciones políticas que contribuyan a la creación de un mundo común y de subjetividades políticas capaces de comprometerse con la construcción de mundos mejores. Además, la resistencia como rasgo de la subjetividad política es una confirmación del dassein heideggeriano que afirma que "no sólo estamos en el mundo sino que hacemos parte de él" (2003), que tenemos un papel activo en el mismo; es concretar la posibilidad histórica de ser siendo y de hacer-se (en) el mundo.

Finalmente, es posible decir que la subjetividad política, ese ámbito propio del sujeto, se configura en lo público y vuelca al sujeto al mundo de lo público, que la subjetivación diluye las fronteras entre el sí mismo y los otros, y que un sujeto que configura la resistencia como rasgo de su subjetividad política es verdaderamente una promesa para el mundo al volverse un sujeto de acciones, acciones que pueden convertirse en la radical novedad en el devenir de la historia:

Aceptar el sueño de un mundo mejor y adherirse a él es aceptar entrar en el proceso de crearlo, proceso de lucha profundamente anclado en la ética, de lucha contra cualquier tipo de violencia, de la violencia contra la vida de los árboles, de los ríos, de los peces, de las montañas, de las ciudades, de las huellas físicas de las memorias culturales e históricas; de la violencia contra los débiles, los indefensos, contra las minorías ofendidas; de la violencia contra los discriminados; de la lucha contra la impunidad que estimula el crimen, el abuso, el desprecio de los más débiles, el desprecio ostensible a la vida; vida que continúa siendo un valor sin precio. (Freire, 2006, p. 146)

\section{Referencias bibliográficas}

Alvarado, S. (2012). Perspectivas epistemológicas y metodológicas de la investigación en infancias y juventudes en América Latina. Módulo virtual-CLACSO. http:// www.clacso.org.ar

Alvarado, S., Ospina, H., Botero, P. y Muñoz, G. (2008). Las tramas de la subjetividad política y los desafíos a la formación ciudadana en jóvenes. Revista Argentina de Sociología, 6(11), 19-43.

Arendt, H. (1995). De la historia a la acción. Barcelona: Paidós

(1997). Qué es la política. Barcelona: Paidós.

(2005). La condición humana. Barcelona: Paidós.

Berger, P. y Luckmann, T. (2001). La construcción social de la realidad. Buenos Aires: Amorrortu.

Cubides, H. (2006). Foucault y el sujeto político: ética del cuidado de sí. Bogotá: Siglo del Hombre Editores.

Freire, P. (2006). Pedagogía de la indignación. Madrid: Morata.

Gadamer, H. G. (1993). El problema de la conciencia histórica. Madrid: Tecnos.

García, D., Restrepo, L. y Urrego, A. (2013). Sentidos entretejidos: una aproximación a la subjetividad política en maestros y maestras (Tesis de maestría). CINDE, Sabaneta.

Giroux, H. (2004). Teoría y resistencia en educación. México: Siglo XXI editores.

Heidegger, M. (2003). Ser y tiempo. España: Editorial Trotta.

Luna, M. (2006). La intimidad y la experiencia en lo público. Medellín: CINDE, U. de Manizales. 
Restrepo, L. (2013). Alteridad, política y pedagogía. Una respuesta ética frente a la existencia del otro (Tesis de maestría). CINDE, Sabaneta.

Ricoeur, P. (2005). Del texto a la acción. México: Fondo de cultura económica.

Skliar, C. (Agosto, 2007). Convivencia, hospitalidad y educación en tiempos desalmados. Revista Novedades Educativas, 18(200), 48-51.

Taylor, Ch. (1996). Las fuentes del yo: la construcción de la identidad moderna. Barcelona. Paidós.

Urrego, A. (2013). La pluralidad: rasgo de la subjetividad política y condición para construir el sentido del "entrenos" (Tesis de maestría). cINDE, Sabaneta. 


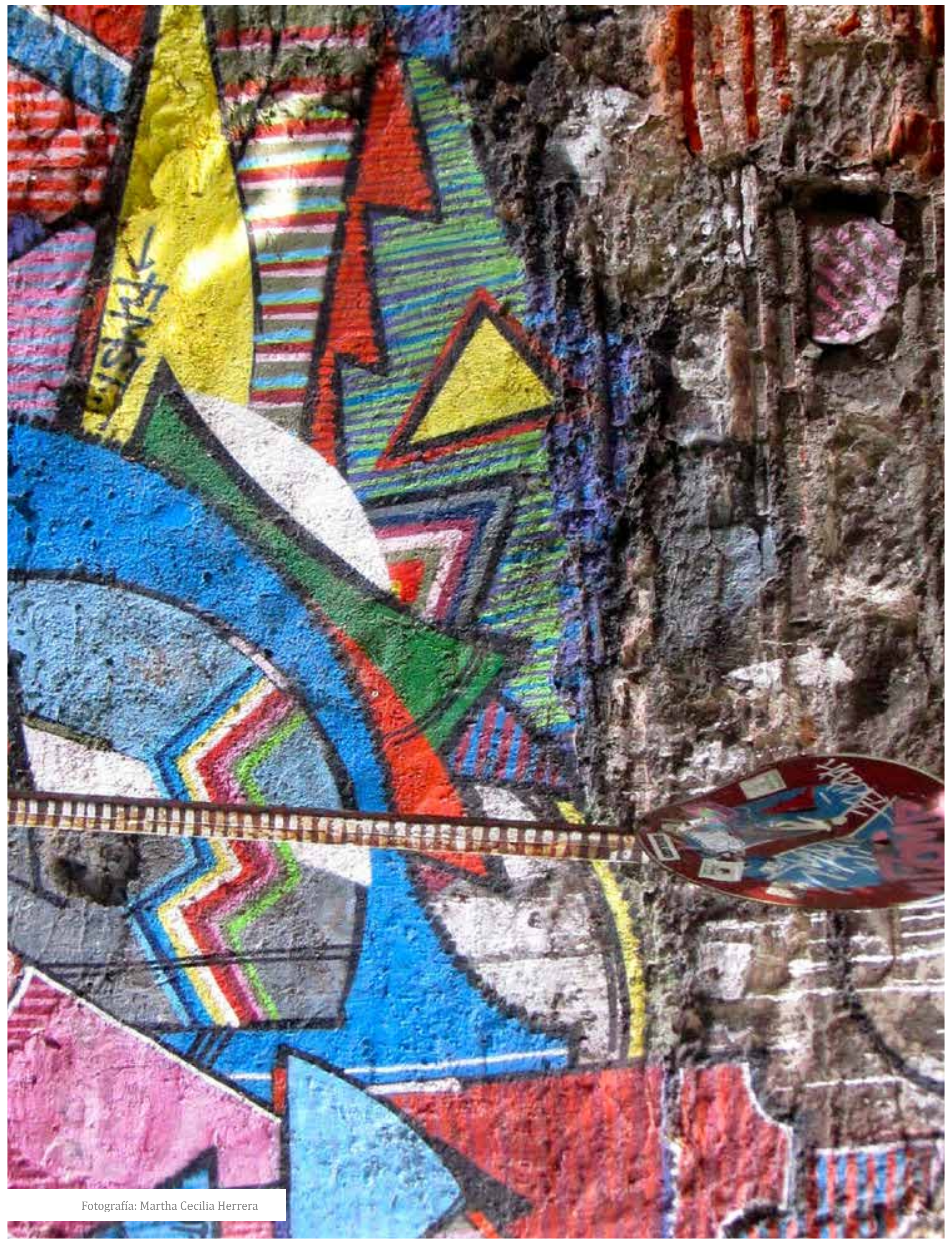

